\title{
LANGUAGE CONTACT AND LANGUAGE CHANGE
}

William M. Cotter

2-20-16

Oman-Zanzibar Teacher Workshop

Center for Middle East Studies - The University of Arizona 


\section{WHAT IS LANGUAGE CONTACT?}

- "The use of more than one language, in the same place, at the same time" (Thomason 2001: 1)

- Contact doesn't require fluency, bilingualism or multilingualism

- It requires contact between speakers of different languages

- Contact also doesn't necessarily require face-to-face contact between speakers of different languages

- Ex. Use of religious resulted in language contact in some communities 


\section{FACE-TO-FACE CONTACT}

- However, language contact is most often a result of face-to-face communication between speakers of two or more languages in a specific area

- Ex. economic migration, trade, slavery

- Language contact always has some kind of social history (even if we don't know it)

- Language contact always has social consequences 


\section{WHERE DOES CONTACT HAPPEN?}

- Everywhere!

- There are really no languages that develop in total isolation

- However, language contact is more intense at certain times and in certain locations

- Some situations of language contact are more stable than others

- Language contact is the norm 


\section{OUTCOMES OF CONTACT}

- Three primary outcomes:

- Contact induced language change

- Language mixture

- Pidgins

- Creoles

- Mixed languages

- Language Death 


\section{CONTACT INDUCED LANGUAGE CHANGE}

- What kind of change counts as contact induced?

- "any linguistic change that would have been less likely to occur outside a particular contact situation is due at least in part to language contact" (Thomason 2001:62)

- There are two primary types of contact induced change:

- Direct importations from a source language

- Indirect effects of contact

- Attrition that sometimes take place in dying languages

- Changes that were initially triggered by an importation

- Caveat: change of this type typically has more than one factor causing it 


\section{LANGUAGE MIXTURE}

- Three main types of language mixture in contact situations:

- Pidgins

- Creoles

- Mixed languages

- Leads to the idea of a 'contact language'

- 'any new language that arises in a contact situation. Linguistically a contact language is identifiable by the fact that its lexicon and grammatical structures cannot all be traced back primarily to the same source language" (Thomason 2001:158) 


\section{PIDGINS \& CREOLES}

- Pidgins and Creoles naturally go together, at least to some extent

- They develop in social situations where there isn't significant bi or multilingualism between the languages used by speakers

- Situations where people of different linguistic backgrounds need to talk to each other regularly 


\section{PIDGINS}

- Typically arise in situations involving speakers of more than two language groups

- They have no shared language,but they need to communicate, often for economic reasons

- Ex. Trade

- But they don't learn each others language, instead a pidgin develops

- The vocabulary of a pidgin is often largely from one of the languages

- However, the grammar doesn't come from any one language 


\section{CREOLES}

- A creole DOES become someone's native language

- But, like pidgins:

- They arise in contact situations where there are speakers of more than two languages

- They typically draw their lexicon from one language

- They draw their grammar from multiple languages that are in contact

- Some pidgins evolve into full fledged creoles

- But not all creoles went through stages where they were pidgins 


\section{MIXED LANGUAGES}

- Arise in situations of bi or multilingualism

- But typically in cases where that bi/multilingualism goes only in one direction

- Some members of a group are able to use the language that is the dominant means of communication in a community

- So there's no need to develop an entirely new language for communication

- The development of a mixed language often serves other social functions:

- The desire/need for an in-group language

- Keeping conversation secret

- Serving as an identity symbol for one group within a community 


\section{LANGUAGE DEATH}

- "Every loss of a language deprives us of a window into the human mind and the human spirit; every language that dies deprives us of a unique repository of human experience and thought. Loss of a language deprives its speech community of much more, because a large part of a culture must inevitably vanish with the language" (Thomason 2001: 223)

- A language dies when it is no longer used for regular spoken communication within a community

- Problems with this:

- What if there's one speaker left?

- Who constitutes a speaker?

- What about language revival? 


\section{APPROACHES TO STUDYING CONTACT}

- "A central debate in contact linguistics surrounds the question of whether linguistic factors or social factors primarily predict the outcomes of contact." (Ravindranath 2015: 244)

- Different scholars treat different factors with varying levels of importance when investigating language contact, but most agree that it's a collection of factors which have an effect in language contact

- Sankoff (2002) 


\section{WHAT FACTORS ARE MOST IMPORTANT?}

- Linguistic factors (King 2002)

- "community studies give us reliable data as to the (social) status of an innovation...[but] an analysis of grammatical change must be responsible to a theory of grammar." Ravindranath 2015:244)

- Social factors (Thomason 2008)

- "the social relations between the two speech communities, not the structures of their languages, determine the direction and the extent of influence" (Ravindranath 2015:244)

- Asking whether change as a result of contact is a given (Poplack and Levey 2010)

- "contact-induced change is not an inevitable, nor possibly even a common, outcome of language contact" (Ravindranath 2015:244) 


\section{CASE STUDY: ARABIC AND HEBREW}

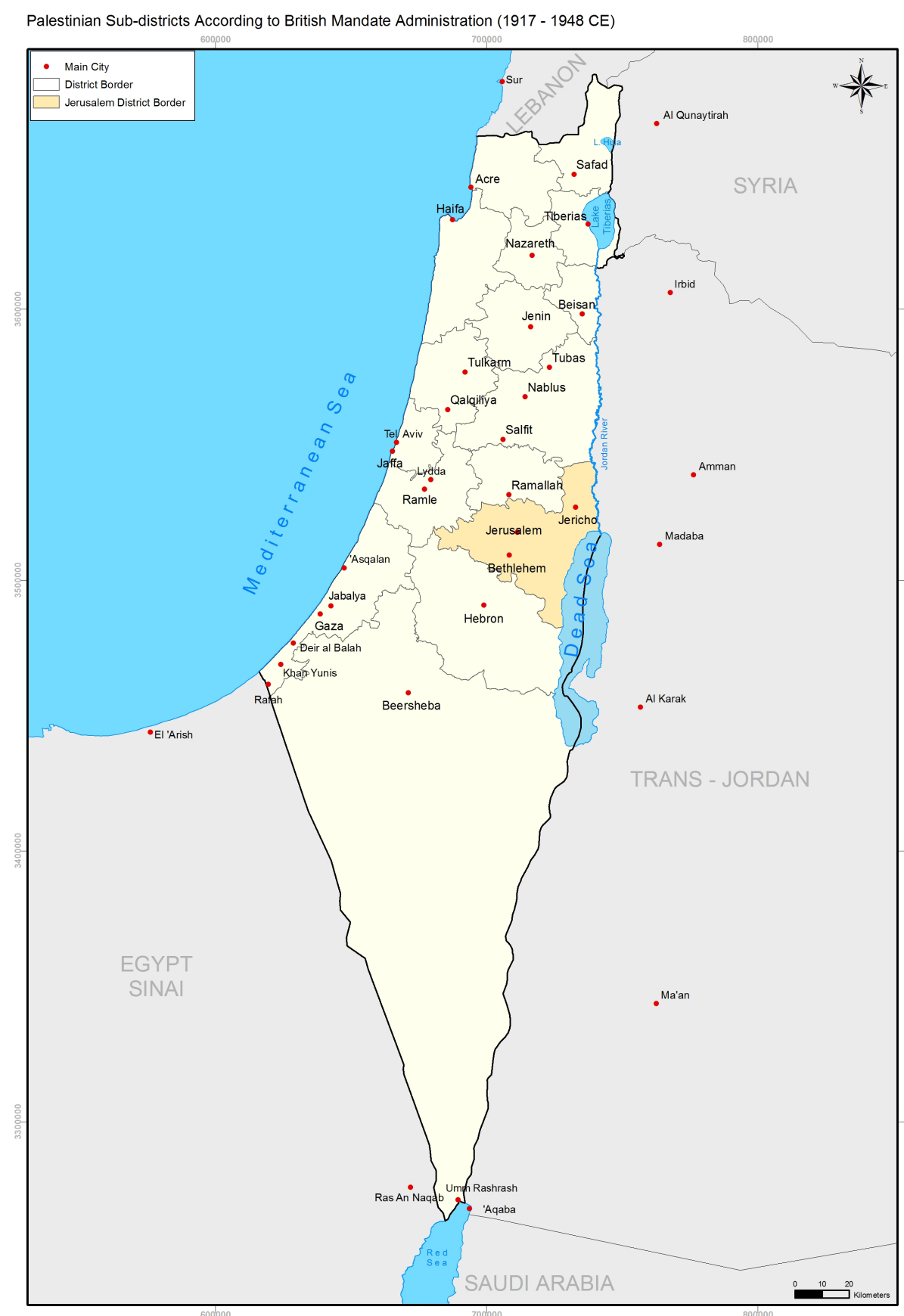




\section{CONTACT SETTING}

- Pre 1948 - Arabic, Hebrew, and English used as official languages

- Post 1948 - Shift towards Hebrew dominance

- Today: Government, education, correctional, and economic systems in Israel are conducted largely in Hebrew

- Speakers of Palestinian Arabic in Israel are often bilingual (at least functionally) in Arabic and Hebrew, and some report being more comfortable using Hebrew (Horesh 2014)

- This system of Hebrew dominance has resulted in change in Palestinian Arabic 


\section{INFLUENCE OF HEBREW ON ARABIC}

- Lenition

- Modern Hebrew lacks the voiced pharyngeal fricative (Arabic 'ayn- $-\varepsilon$ )

- As a result of contact between the two languages, Arabic speakers appear to be losing this sound in their varieties of Arabic (Horesh 2014)

- Depharyngealization

- The Arabic 'emphatics' may be 'losing their emphatic'

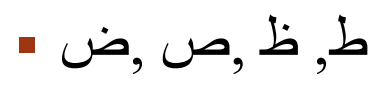

- Borrowings

- Hebrew words are replacing common words in Palestinian Arabic 


\section{INFLUENCE OF AREBIC ON HEBREW}

- Influence of Arabic on Hebrew is notably more limited

- Some borrowing of Arabic words into Hebrew (ex. 'yalla')

- Mostly slang and vernacular

- Structural borrowing from Arabic is limited

- The lack of influence of Arabic on Hebrew reflects the directionality of bilingualism in Israel, as well as the dominant status of Hebrew (Henkin 2011) 


\section{CONCLUSIONS}

- Language contact is a complex process

- There is virtually always more than one source of contact induced change

- And there are numerous different outcomes of contact, depending on the conditions under which that contact takes place

- Finally, there are a number of different ways that scholars have investigated contact, and there is substantial debate about what should be considered the primary factor(s) that influence contact 


\section{REFERENCES}

- Horesh, Uri. 2014. Phonological outcomes of language contact in the Palestinian Arabic dialect of Jaffa. Ph.D. Thesis. Colchester: University of Essex

- Henkin-Roitfarb, Roni. 2011. Hebrew and Arabic in Asymmetrical Contact in Israel. Lodz Papers in Pragmatics 7(1): 61-100

- King, Ruth. 2002. Crossing grammatical borders: tracing the path of contact-induced change. Paper presented at the Eleventh International Conference on Methods in Dialectology, 5-9 August 2002, University of Joensuu, Finland.

- Poplack, Shana and Levey, Stephen. 2010. Contact-induced grammatical change: a cautionary tale. Language and space. An international handbook of linguistic variation, Vol. 1 : theories and methods, eds. by Peter Auer and Jürgen Erich Schmidt, 391-419. Berlin: DeGruyter Mouton.

- Ravindranath, Maya. 2015. Sociolinguistic Variation and Language Contact. Language and Linguistics Compass 9(6): 243-255.

- Sankoff, Gillian. 2002. Linguistic outcomes of language contact. The handbook of language variation and change, eds. by J. K. Chambers, Peter Trudgill and Natalie Schilling-Estes, 638-668. Oxford, UK: Blackwell.

- Thomason, Sarah G. 2001. Language Contact. Edinburgh: Edinburgh University Press

- Thomason, Sarah G. 2008. Social and linguistic factors as predictors of contact-induced change. Journal of Language Contact - THEMA 2: 42-56. 